\title{
Meaning of Social Media Applications in Interaction with Fellow Users
}

\author{
Dr. Ido Prijana Hadi \\ ido@petra.ac.id
}

Faculty of Communication Science, Petra Christian University

\begin{abstract}
The era of using gadgets and the freedom to access and publish information is increasingly massive. The existence of application media today has become a medium of communication, both for individuals and socially. Direct interaction is no longer seen as the best way to communicate. They have been included in the terminology of onLine communication. This condition is mutual symbiosis, can be studied in different perspectives. Technology influences human or human behavior as users who must control technology. This study looks at the second side, namely how humans as social actors use communication technology. The purpose of this study was to find out how the meaning of the users of social whatsapp and line media applications in daily interactions from various professions. This study uses the interpretive constructionist paradigm, a qualitative approach to phenomenological methods. The results of this study indicate that users interpret social application media to facilitate communication, information sharing, and establish social relationships. The implication that arises is that face-to-face interaction is no longer an obstacle or necessity for various user professions. Connection is a representation of the presence of face-to-face interaction.
\end{abstract}

Keywords: Social Media Application, Social Relationships, Phenomenology.

\section{Introduction}

The development of media applications with the Android operating system, eventually became an application for social media (social media apps), which can reach individuals or groups. Not a few implications which then affect the perception, attitude and behavior of interaction between users. Seeing this reality, there is no denying that the media is ubiquitous, everywhere. Indirectly, whatever information comes into our heads becomes a real picture. As Lippmann [1] said, the world outside, the pictures in our heads. People's attitudes and opinions are often influenced by the media.

Based on the results of previous research by Alyusi [2] with the positivistic paradigm, about the online community of Kaskus, it was obtained the results that activities that are often carried out by members are information sharing. For someone to update information can reduce uncertainty. Social media is used as a benefit for discussion through the rules that apply. If a member violates the provisions by disseminating information about ethnicity, religion, race and between groups, then he will be banned or dismissed as a member.

A study at the University of California, Los Angeles, quoted by Stuart Wolpert at the UCLA Newsroom, found that students who avoided electronic devices were better able to recognize human emotions than students who spent hours using electronic equipment. This finding is consistent with the opinion of Fowlkes about the importance of in-person communication. Because social media destroys people's social skills and reduces face-to-face interaction [3]. The state of the art in this study refers to what is done by the research company comScore [4] which performs onLine audience measurement standards, including the use of mobile applications in Indonesia. On March 29, 2017, comScore reported their first research results with data in January 2017. The results stated that the Whatsapp chat 
application is the most popular mobile application in Indonesia with the most users, after the mandatory application of Android users, namely Google Play. According to comScore, Whatsapp already has around 35.8 million users in Indonesia.

This is the attraction of social media studies in this study. Where research looks not at social media in general, but in the media of mobile applications. In some literature often referred to as the mobile messaging app, registered members can exchange various types of messages with all the contacts that users have through their service provider. Typically, the mobile application provides multimedia communication with text messages, free video chat, for-talk voice messaging, photo/video sharing, location sharing, and exchange of contact information.

Based on these arguments, this research was conducted to reveal the meaning and reasons for using social media applications. The focus of the interesting research question to be explored from this communication phenomenon is how does the use of social media applications mean in the interaction of various fields of professional users? The benefits in phenomenological study research in relation to social media applications are expected to be able to provide theoretical contributions to phenomenological studies in media studies (application media and users) related to the interaction (communication) of the user's profession.

\section{Conceptual Background}

\subsection{Social Phenomenology}

Phenomenology became a branch of philosophy, where Edmund Husserl published philosophically. Phenomenological philosophy then has implications for the thought of Social Sciences and Humanism, including Communication [5]. Alfred Schutz (1899-1959), an Edmund Husserl's student, then developed as a theory, as well as a more operational approach, especially for social science research, including communication research [6]. His effort to develop social phenomenology is to examine the ways in which community members form and reshape the realms of everyday life. He emphasized that awareness and interaction are mutually shaped. Affirmed by Denzin \& Lincoln [7] the provision of knowledge is the only source that allows each individual to interpret experiences, understand the intentions and motivations of other individuals, gain inter subjective understanding, and ultimately seek action.

Phenomenology assumes that humans are creative creatures, free-willed, and have several other subjective properties. The main idea of phenomenology is that people will actively interpret their experiences by giving meaning to what they see. Interpretation is an active process in giving meaning to something that is observed, such as a text, an action, or a situation, all of which can be called experience. Because a message or action can mean many things, meaning cannot be simply "discovered".

Humans as social beings certainly have an awareness of the world of their daily lives as a social awareness. Humans are required to be able to understand each other and their social actions. In social research, researchers are research instruments that ultimately make interpretation of the observed reality. Researchers try to enter into the world of interpretation of people who are the subject of research. Researchers are involved cognitively with people who are observed and explain scientifically this process [8].

\subsection{Social Media and Social Media Application}

Communication experts say that the various definitions of social media that exist today are so broad. This shows the complexity, the point of attention, and its ability to be applied 
outside the discipline of knowledge. Some notions of social media have been formulated by various parties, both in communication studies and other studies. Brogan [9] defines social media ". . . is a new set of communication and collaboration tools that enable many types of interactions available (social media is a new communication device and collaboration tool that allows many types of interactions, which were not previously available to ordinary people). While Mayfield [10] states that social media (in the broadest sense) is best understood as a group of new types of online media, which are mostly to share or have the characteristics of participation, openness, conversation, community, and connectedness.

Literature studies often refer to Whatsapp and Line as a messaging apps or addictive applications [11]. We find ourselves from time to time always using Whatsapp. From morning and before bed at night, at home, at work, on the road, at meal times, etc., all of our presence is similar in status to social media. Whatsapp and Line, as a mobile application is so popular. Even becoming a mobile application for social purposes. This application is a kind of 'need' that is used in the life of everyday interaction, replacing the SMS feature that has been left behind by many users. When viewed from smartphone users with Android and iOS operating systems, both applications become a kind of obligation that must be in the user's device. Based on these arguments, researchers prefer to call whatsapp and line as a social media application. A terminology that refers to the application of an Android-based system that is used by users for the benefit of individual or social interactions. Social media applications like WhatsApp are also interactive web 2.0 applications that can be accessed online through https://web.whatsapp.com/. Whatsapp facilitates social interaction through text, voice or video. But the social interaction is limited to recipients sent to someone or group, as the intention of the sender.

\section{Method}

Research uses the interpretive paradigm, qualitative research approaches with phenomenological methods are focused on the construction of deep experience and understanding from users of social media on what they do and face in their daily lives. in mobile application media, everyday reality. Research subjects selected individuals who become users of social media applications and have accounts on Whatsapp and Line. Data collection uses in-depth interviews of 10 participants from various job professions, such as soldier, lecturer, teacher, nurse, police, employee, event coordinator, doctor, entrepreneur, and manager. Information provided by participants and accepted by researcher was information as it occurred in the lives of meaningful social actions. The subject of the study as well as the analysis unit is the experience or narratives of the story obtained from individuals who were the participants of the study.

\section{Findings and Discussion}

4.1. Users utilize the Whatsapp and Line applications to facilitate communication, information sharing and establish social relationships.

Social media applications such as WA and Line have been so popular in the wider community, including the research participants. On average, they have been using social media applications since 2012 until this research was conducted in 2018. Or as users of this social media application range from 2.5 years to 3 years, while time span used to consume social media applications was 1-12 hours per day. Especially for Whatsapp use, participants use it to communicate with family, with friends, and work interests.

The dynamics of users of social media applications develop in line with the demands of the dynamics of society and industry. That is, the community uses application technology to 
facilitate and assist various needs. Social media applications are so popular with its users, because they were practical to share information; easy to use; cheap; efficient in the sense that social media applications are appropriate; suitable for doing (producing) something that is efficient (not wasting time, effort, costs); effective to convey the message, in the sense that the effect was effective because communication was quickly conveyed. Users did not know the time when accessing this social media application. Users use this social media application to form personal relationships and the way people develop social networks.

On the other hand, by referring to social media terminology, social media is called if there are interactive features that facilitate social interaction through text, sound, video or other digital modes. Communication participants are acting together and are mutually active with each other in sending messages. Or circumstances characterized by exchanges of conversations in social media applications. The term terminology of interactivity refers to the characteristics of the website. Where in the characteristics of interactive websites such as users can modify their own messages to be delivered. By investigating deeper to users, the Whatsapp application was able to provide added value to users in the speed of communication. Like web-based social media such as Facebook, Twitter, Instagram, Linkedin, Tumblr, YouTube, Vimeo, Google +, Periscope, Kaskus, and so on.

Users sacrifice real-world conversation experience and understanding just to stay connected (online connection) continuously on social media applications. This connection is not limited to being an adequate substitute for face-to-face interaction among users of social media applications, because it is easier to do. As social beings, digital communication cannot be the same as real communication. The level of emotional attachment is different from when meeting face to face. However sophisticated the tools we use, direct interaction is still very important in human life.

Interaction in social media applications still cannot replace real-world interactions, although it has connections with many people. This application is just a substitute for the real world. Because consumers use applications on their smartphones, similar to the number of people who access and use social media such as Facebook. Social media applications are online networks limited to interacting, connecting and fostering relationships virtually and forming communities. The intensity of interactive communication in this limited "social network" is very dependent on the condition of the active telephone number. In the sense of verifying telephone numbers as users of social media applications becomes very important. Active participation of users in social media applications for personal and community relations, depending on the system.

In general, the use of social media applications is able to meet their social needs to be limited to interconnected. This is done so they can maintain their social relations. Meanwhile, if someone wants to try to maintain a realistic relationship, it must be able to accept others in its complexity. With real life conversations, humans learn to overcome the shortcomings and complexity of others, and vice versa. Users see in terms of convenience and generosity the cost of use. Such as for social networking (Whatsapp group), media sharing (consultation or information sharing), social news (information facilities / notifications), discussion forums (means of exchanging ideas / ideas), and so on. Affirmed by Mayfield [10] when it comes to social media, this can be seen as a better two-way way of communicating for its users. Includes close relations in two-way and multi-way communication.

Another aspect of using social media applications is to access news or information. Almost all participants of this study said that they used Line to fill their free time by reading Line Today as news information media. What is shown by Line Today, uses what is called curative journalism. The word "curation" means gathering all fragmented pieces of information to one location, allowing people to gain access to more specific content. News media organizations have curation as core competencies (referrals). The editor arranges information for readers. As confirmed by Guallar [12] the concept of content curation in 
journalism refers to journalistic pieces, parts or even media, in addition to their own content, including (publishing or using) selected content from various sources. News from various sources will be made together to form complete news. While, the role of news agencies collaborates in contributing to official news. Content curation can be considered as an evolution of what happened on that day, accepting the name "link journalism", encouraging trends not only including links to official and other sources in published news, but also unusual in journalism to source from other media.

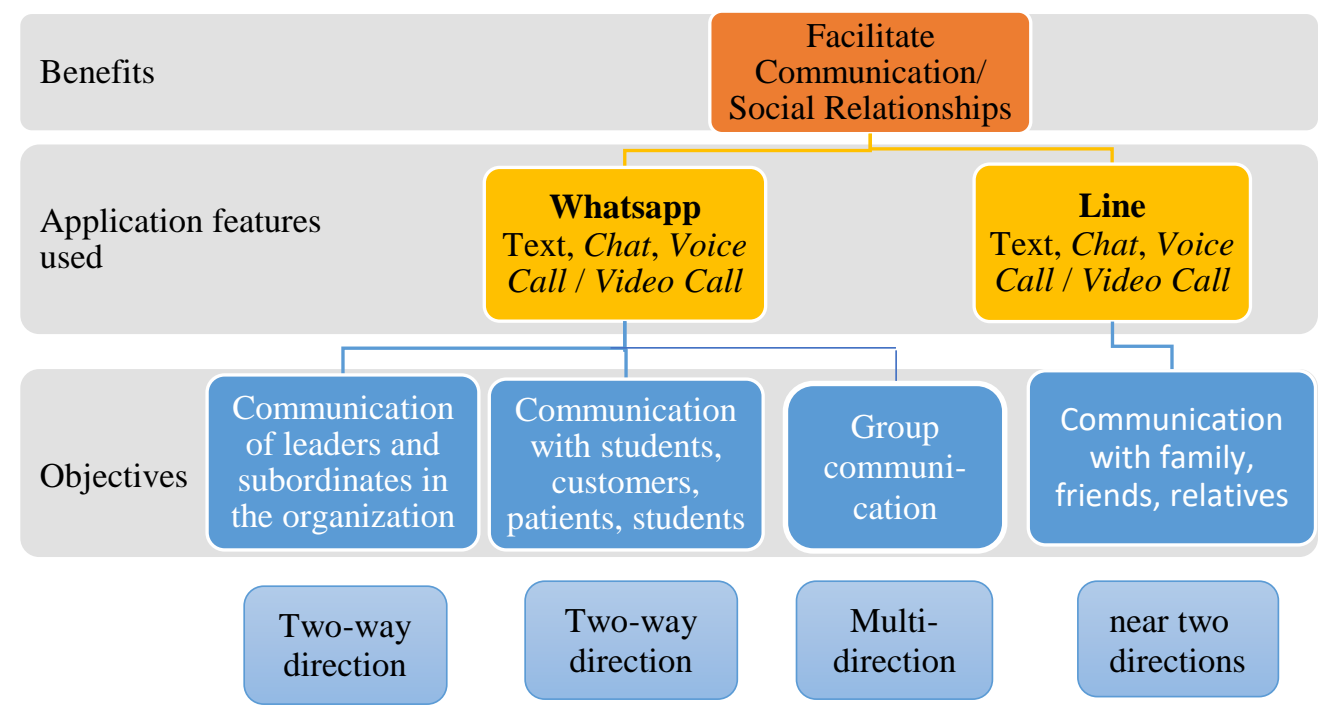

Fig. 1. Communication Patterns of Users in Using Social Media Applications

\section{Conclussion}

The meaning of the use of social media applications in the interaction of various fields of professional users can be summarized as follows. Users use the Whatsapp and Line application to facilitate communication, share information and develop social relationship. Communication patterns practiced more in two directions users understand Whatsaap and Line applications as a useful medium for information sharing. Work completion was helped because between leaders and subordinates can be directly mediated in mutual communication. Besides being practical, it was very efficient because it did not require telephone pulses, only internet packages. Users interpret social media applications as a medium to establish social relationships and read news.

\section{References}

[1] W. Lippmann, Public opinion, 2nd ed. New Brunswick: Transaction Publishers, 1998.

[2] S. D. Alyusi, Media sosial: Interaksi, identitas dan modal sosial, 1st ed. Jakarta: Prenadamedia Group, 2016.

[3] E. Reeves, "Social media affects human interaction," 2015. [Online]. Available: http://www.studentprintz.com/social-media-affects-human-interaction/.[Accessed: 04Sep-2015].

[4] Comscore, "comScore announces launch of MMX multi-platform, as well as major 
enhancements to mobile metrix in Indonesia with introduction of mobile consumer panel data,” 2017. [Online]. Available: https://www.comscore.com/Insights/PressReleases/2017/3/comScore-Announces-Launch-of-MMX-Multi-Platform-Indonesia. [Accessed: 08-Aug-2018].

[5] K. A. Littlejohn, Stephen W \& Foss, "Phenomenology," Encyclopedia of Communication Theory. Sage Publications, Inc., California, p. vi, 2009.

[6] A. . Miller, Phenomenology of spirit by G.W.F. Hegel. London: Oxford University Press, 1977.

[7] N. K. Denzin and Y. S. Lincoln, Handbook of qualitative research, Trans. Yogyakarta: Pustaka Pelajar, 2009.

[8] E. Kuswarno, Fenomenologi, metodologi penelitian komunikasi, konsepsi, pedoman, dan contoh penelitian: Fenomena pengemis kota Bandung, 1st ed. Bandung: Widya Padjadjaran, 2009.

[9] B. Chris, Social media 101: Tactics and tips to develop your business onLine. New Jersey: John Wiley \& Sons, 2010.

[10] A. Mayfield, "What is social media?," 2008. [Online]. Available: http://www.icrossing.co.uk/fileadmin/uploads/eBooks/What_is_Social_Media_iCrossi ng_ebook.pdf. [Accessed: 28-Aug-2018].

[11] P. Turay Jr, "Are messaging apps considered social media?," Linkedin, 2016. [Online]. Available: https://www.linkedin.com/pulse/messaging-apps-consideredsocial-media-peter-turay-jr. [Accessed: 21-Oct-2017].

[12] J. Guallar, "Content curation in journalism," Hipertext.net, vol. 12, 2014. 